\title{
Dynamics of One-Cycle Controlled Ćuk Converters
}

\author{
Keyue M. Smedley, Member, IEEE, and Slobodan Ćuk, Senior Member, IEEE
}

\begin{abstract}
One-Cycle Control is a nonlinear control method. The Flow-Graph modeling technique is employed to study the large-signal and small-signal dynamic behavior of One-Cycle Controlled switching converters. Systematic design method for One-Cycle Control systems is provided with the Cuk converter as an example. Physical insight is given which explains how OneCycle Control achieves instant control without infinite loop gain. Experimental results demonstrate that a Cuk converter with OneCycle Control rejects the power source perturbation in one-cycle and the average of the diode voltage follows the control reference in one cycle.
\end{abstract}

\section{INTRODUCTION}

$\mathbf{O}$ NE-CYCLE Control is a large-signal nonlinear control method developed for switching circuits and systems [1]-[3]. An One-Cycle Controlled switch has the ability to reject the input perturbation and to follow control reference instantly. There is no steady-state error and nor dynamictracking error between the control reference and the average value $^{1}$ of the switched variable. Furthermore, when an OneCycle Controlled switch is embedded in a complex system such that the input of the switch is a function of other state variables, the zero-error property is preserved in the steady-state and in a transient within the converging region. One might assume that such a system has infinite loop-gain; however, a physical system is usually unstable with infinite loop-gain due to its limited frequency bandwidth. How does the One-Cycle Control work? In this paper, the Flow-Graph technique [4] is used to study the dynamic behavior of a OneCycle Controlled Ćuk converter and to explain why instant control is possible and how to design such systems. The OneCycle Control method is briefly reviewed in Section II. The global dynamic behavior of the One-Cycle Controlled Ćuk converter is examined in Section III and the small-signal loop-gain is studied in Section IV. Experimental results are provided in Section V. Summary and discussions are given in Section VI.

\section{ReVIEW OF ONE-CyCle CONTROL Method}

A switch operates according to a switch function $k(t)$ at a switching frequency $f_{s}=\frac{1}{T_{s}}$,

$$
k(t)=\left\{\begin{array}{cc}
1 & 0<t<T_{\mathrm{ON}} \\
0 & T_{\mathrm{ON}}<t<T_{s}
\end{array}\right.
$$

Manuscript received September 22, 1993; revised June 13, 1995.

K. M. Smedley is with the Department of Electrical and Computer Engineering, University of California, Irvine, Irvine, CA 92717 USA.

S. Cuk is with the Power Electronics Group, California Institute of Technology, Pasadena, CA 91125 USA.

IEEE Log Number 9514901.

${ }^{1}$ The average value of a switched variable is defined as the average in one switching cycle in this paper.

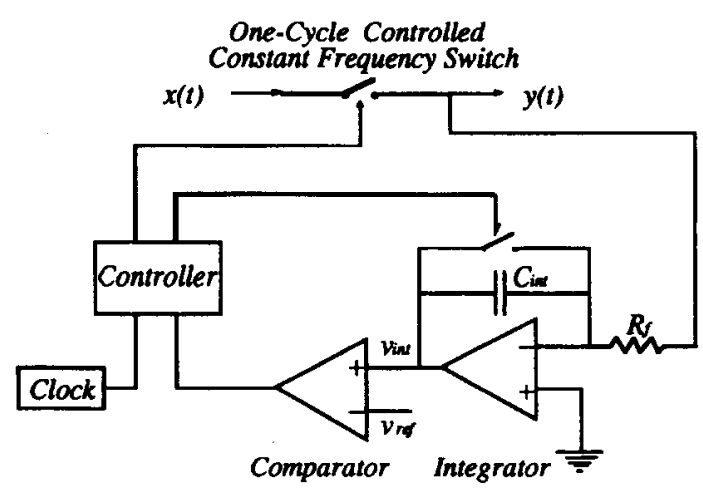

Fig. 1. The One-Cycle Controlled constant frequency switch.

In each cycle, the switch is on for a time duration $T_{\mathrm{ON}}$ and is off for a time duration $T_{\mathrm{OFF}}$, where $T_{\mathrm{ON}}+T_{\mathrm{OFF}}=T_{s}$. The input signal $x(t)$ of the switch is chopped by the switch and transferred to the output node of the switch to form a switched variable $y(t)$. The frequency and the pulse width of the switched variable $y(t)$ is the same as that of the switch function $k(t)$, while the envelope of $y(t)$ is the same as that of the input signal $x(t)$. The duty-ratio $d=\frac{T_{\mathrm{ONN}}}{T_{s}}$ is modulated by an analog control reference $v_{\text {ref }}(t)$.

If the duty-ratio of the switch is modulated such that the integration of the switched variable is exactly equal to or proportional to the control reference in each cycle, i.e.

$$
k \int_{0}^{T_{\mathrm{ON}}} x(t) d t=v_{\mathrm{ref}}(t)
$$

where $k$ is a constant, the average of the switched variable will be exactly equal to or proportional to the control reference, since the switching frequency is a constant.

$$
y(t)=\frac{1}{T_{s}} \int_{0}^{T_{\mathrm{ON}}} x(t) d t=K v_{\mathrm{ref}}(t)
$$

where $K=\frac{1}{k T_{s}}$ is a constant. The technique to control switches according to this concept is defined as the One-Cycle Control technique. A typic implementation circuit is shown in Fig. 1. The integration starts the moment when the switch is turned on by the fixed frequency clock pulse. The integration value,

$$
v_{\text {int }}=k \int_{0}^{t} x(t) d t
$$

is compared with the control reference $v_{\text {ref }}(t)$ instantaneously. At the instant when the integration value $v_{\text {int }}$ reaches the control reference $v_{\text {ref }}(t)$, the controller turns off the switch and resets the integrator to zero. With One-Cycle Control, the effective output signal of the switch is

$$
y(t)=K v_{\text {ref }}(t) .
$$




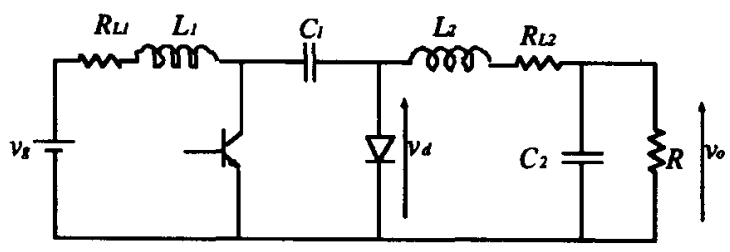

Fig. 2. Ćuk converter.

An One-Cycle Controlled switch is globally stable, since its input signal and the control reference are independent variables. The One-Cycle Controlled switch fully rejects the input signal and linearly all-passes the control signal $v_{\text {ref. }}$ In addition, an One-Cycle Control led switch automatically corrects the switching error due to on-state resistance, switching delay, and the turn-on and turn-off transients. Therefore, the One-Cycle Control technique turns a nonlinear switch into a linear path.

\section{Global Dynamics of One-Cycle CONTROLLED ĆUK CONVERTER}

An One-Cycle Controlled switch is globally stable, since its input signal and the control reference are independent variables. However, if the One-Cycle Controlled switch is embedded in a complex system such that the input signal of the switch is a function of other state variables, the stability for the system may not be global.

One-Cycle Control is a nonlinear control method. The nonlinear modeling technique, Flow-Graph, developed at Caltech, is used to study the dynamics of the One-Cycle Control switching converters. This modeling method interprets a physical switching converter into a Flow-Graph. A switching converter usually contains more than one signal switch in its FlowGraph. For a two switch-state converter, all signal switches are either synchronized or complementary to one anther, since they are implemented by one transistor and one or more diodes in the real circuit, where the transistor serves as a master switch and the diodes serve as slave switches. In this case, the control reference is one dimensional and only one signal switch can be One-Cycle Controlled. The other signal switches are turned on and off according to the state of the One-Cycle Controlled signal switch. A Ćuk converter shown in Fig. 2, for instance, contains four signal switches in its switching Flow-Graph, two current switches and two voltage switches, as shown in Fig. 3.

Any signal switch can be selected for One-Cycle Control, current or voltage depending on the application of the circuit. For instance, if the signal switch, in the path from Node $v_{C 1}$ to the Node $v_{d}\left(v_{d}=v_{L 2}+v_{o}\right)$, is chosen as the One-Cycle Controlled switch, the input signal of the switch $v_{C 1}$ will be fully rejected or blocked by the One-Cycle Controlled switch; therefore, the forward signal path is broken into two. The resulting system includes two second-order systems: the input loop and the output loop, as shown in the Switching FlowGraph in Fig. 4. The output signal of the One-Cycle Controlled switch is the diode-voltage; hence, it is One-Cycle Control of the diode-voltage.

Any dynamics in the input loop are blocked by the OneCycle Controlled switch. The output loop is fully controlled by the control reference. It is equivalent to a linear second-order

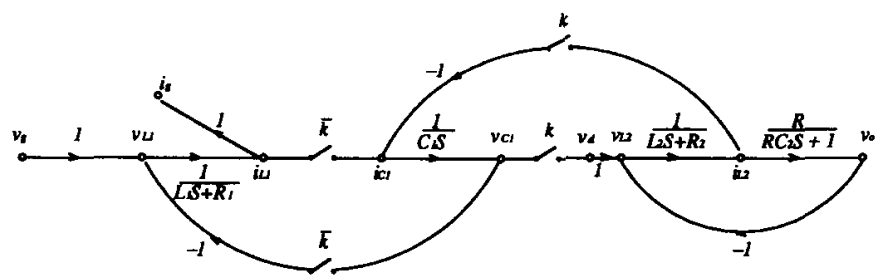

Fig. 3. The signal flow-graph of Ćuk converter.

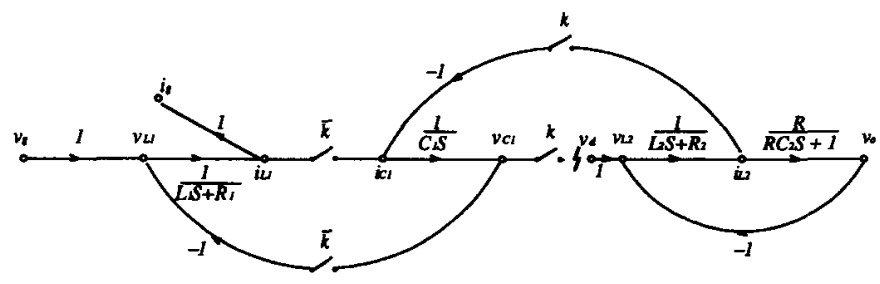

Fig. 4. Diode-voltage One-Cycle Control.

system from the control reference to the output voltage. The input loop is influenced by the output loop through the switch in the path from Node $i_{L 2}$ to Node $i_{C 1}$. Since the signal $i_{L 2}$ is independent of the input loop dynamics, the path from Node $i_{L 2}$ to Node $i_{C 1}$ is not included in the loop. Hence, the stability of the input loop is not affected by the dynamics of the output loop.

The stability of the One-Cycle Controlled Ćuk converter depends on the stability of the two loops. The output loop, which is a second-order linear system, is globally stable. Since the input loop is a nonlinear second-order system, its stability may not be global.

The average of the switched variable, the diode voltage, is

$$
v_{d}=\frac{1}{T_{s}} \int_{0}^{d T_{s}} v_{C 1} d t=d v_{C 1} .
$$

Since the One-Cycle Controlled switch all-passes the control reference $v_{\text {ref }}$ and fully rejects its input signal $v_{C 1}$, that is

$$
v_{d}=v_{\text {ref }} .
$$

As a result, the duty-ratio of the One-Cycle Controlled switch is modulated by the following equation

$$
d=\frac{v_{\text {ref }}}{v_{C 1}} .
$$

The duty-ratio of the One-Cycle Controlled switch is a nonlinear function of the voltage across the input capacitor. Since all the other switches are either synchronized or complementary with the One-Cycle Controlled switch, their duty-ratio is also determined by the nonlinear feedback signal $d=\frac{v_{\text {ref }}}{v_{C 1}}$. The input loop and the output loop have the structure in the largesignal model shown in Fig. 5. The state-space equations for the input loop are obtained from Fig. 5.

$$
\begin{aligned}
L_{1} \frac{d i_{L 1}}{d t} & =v_{g}-R_{1} i_{L 1}-(1-d) v_{C 1} \\
C_{1} \frac{d v_{C 1}}{d t} & =(1-d) i_{L 1}-d i_{L 2} \\
d & =\frac{v_{\text {ref }}}{v_{C 1}} .
\end{aligned}
$$




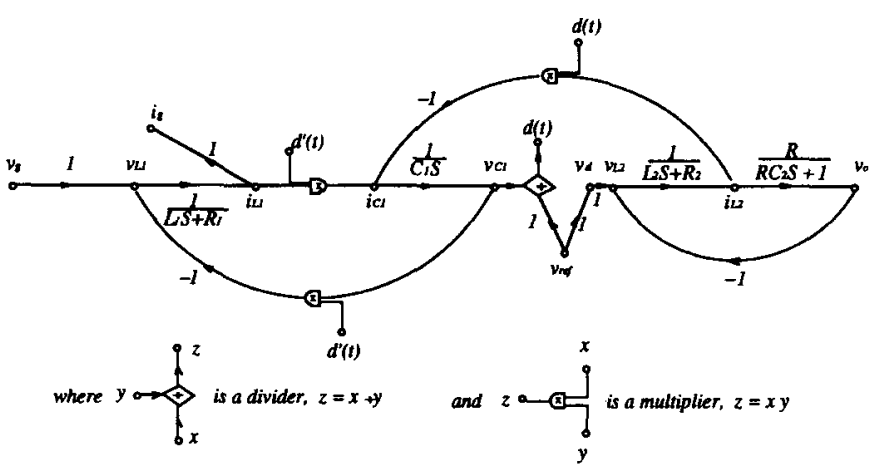

Fig. 5. The large-signal model of the One-Cycle Controlled ĆĆuk converter.

Let (9) and (10) equal zero, that is

$$
\begin{aligned}
v_{g}-R_{1} i_{L 1}-(1-d) v_{C 1} & =0 \\
(1-d) i_{L 1}-d i_{L 2} & =0 \\
d & =\frac{v_{\text {ref }}}{v_{C 1}} .
\end{aligned}
$$

Equations (11)-(13) reveal two singular points, $P_{1}$ and $P_{2}$, and a singular region $v_{C 1}=0$.

The global dynamic behavior, modeled by the Flow-Graph and simulated using the TUTSIM program [6], is shown in Fig. 6 , where the the $x$-axis represents the voltage across the input capacitor $v_{C 1}$ and the $y$-axis represents the input inductor current $i_{L 1}$. There are two singular points, $P_{1}=\left(V_{1}, I_{1}\right)$ and $P_{2}=\left(V_{2}, I_{2}\right)$, and a singular region, the whole $i_{L 1}$-axis. $P_{1}$ is a stable spiral point and $P_{2}$ is an unstable saddle point. The lower part of the $i_{L 1}$-axis is an unstable region, and the upper part of the $i_{L 1}$-axis is stable. The system is not globally stable. The region around the spiral point $P_{1}$ is the desired working region.

In practice, there are physical restrictions on the duty-ratio, $D_{\min } \leq d \leq D_{\max }$, due to the switching time limitation. When $v_{C 1} \leq \frac{v_{\mathrm{ref}}}{D_{\max }}$, the system operates at the maximum duty-ratio $D_{\max }$; therefore, the system becomes a linear system

$$
\begin{aligned}
L_{1} \frac{d i_{L 1}}{d t} & =v_{g}-R_{1} i_{1}-\left(1-D_{\max }\right) v_{C 1} \\
C_{1} \frac{d v_{C 1}}{d t} & =\left(1-D_{\max }\right) i_{L 1}-D_{\max } i_{L 2} .
\end{aligned}
$$

When $v_{C 1} \geq \frac{v_{\text {ref }}}{D_{\min }}$, the system operates at the minimum duty-ratio $d_{\min }$; therefore, the system becomes a linear system

$$
\begin{aligned}
L_{1} \frac{d i_{L 1}}{d t} & =v_{g}-R_{1} i_{1}-\left(1-D_{\min }\right) v_{C 1} \\
C_{1} \frac{d v_{C 1}}{d t} & =\left(1-D_{\min }\right) i_{L 1}-D_{\min } i_{L 2} .
\end{aligned}
$$

If the maximum duty-ratio is artificially restricted such that $D_{\max }<\frac{v_{\text {ref }}}{V_{2}}$, the unstable saddle point $P_{2}=\left(V_{2}, I_{2}\right)$ is avoided. Therefore, the system becomes globally stable. The global dynamics are shown in Fig. 7 , where the the $x$-axis represents the voltage across the input capacitor $v_{C 1}$ and the $y$-axis represents the input inductor current $i_{L 1}$. The resulting system is piecewise controlled. In the converging region $V_{2}<$ $v_{C 1}<\frac{v_{\text {ref }}}{d_{\min }}$, the system is One-Cycle Controlled, while in the regions $v_{C 1}<V_{2}$ and $v_{C 1}>\frac{v_{\text {ref }}}{d_{\min }}$, the system is controlled with a fix duty-ratio.

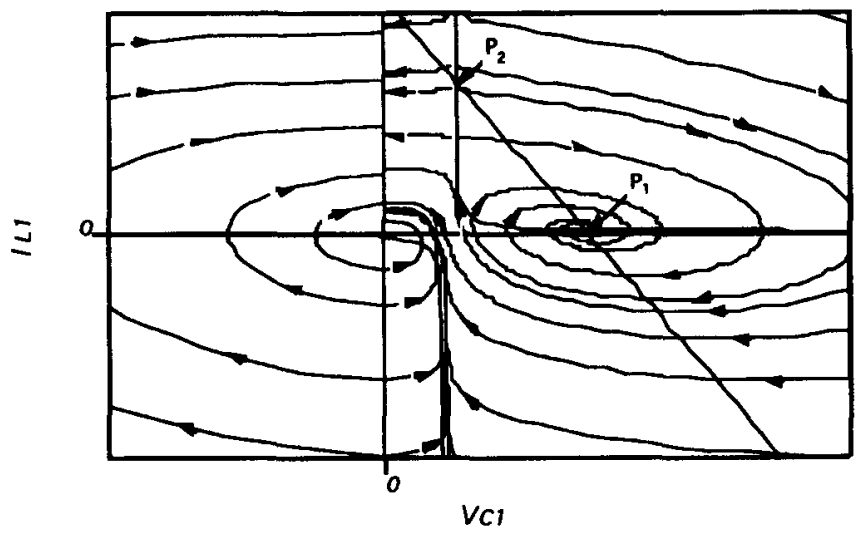

Fig. 6. The global dynamic behavior of the One-Cycle Controlled Cuk converter.

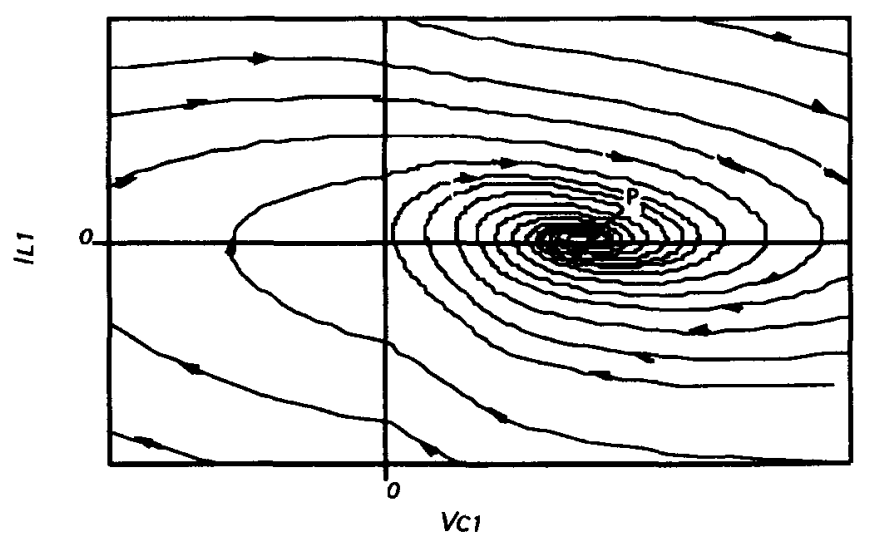

Fig. 7. The global dynamic behavior with duty-ratio limitation.

\section{LOCAL DYNAMIC BEHAVIOR}

For a linear feedback system, an infinite loop-gain is required in order to achieve instant control over any state variable. In practice, all physical systems have limited band width. Consequently, when the loop-gain is higher than a certain value, the loop becomes unstable. Therefore, it is impossible to have instant control for a linear feedback control system.

However, instant control is achievable by One-Cycle Control. For the One-Cycle Controlled Ćuk converter, the average value of the diode-voltage instantly responds to the control reference, and there is no steady-state error nor dynamic error between the control reference and the average of the diode-voltage in the converging region. To further understand One-Cycle Control, a zoom-in study of the linearized local dynamic behavior and the loop-gain in the converging region is necessary. The large-signal model of the One-Cycle Controlled switch function is given in (8). Suppose the One-Cycle Controlled switch operates around the steady-state point, $V_{\text {ref }}$, $V_{C 1}$, and $D$ with small-signal perturbations, $\hat{v}_{\text {ref }}, \hat{v}_{C 1}$, and $\hat{d}$.

$$
\begin{aligned}
v_{\text {ref }} & =V_{\text {ref }}+\hat{v}_{\text {ref }} \\
v_{C 1} & =V_{C 1}+\hat{v}_{C 1} \\
d & =D+\hat{d} .
\end{aligned}
$$




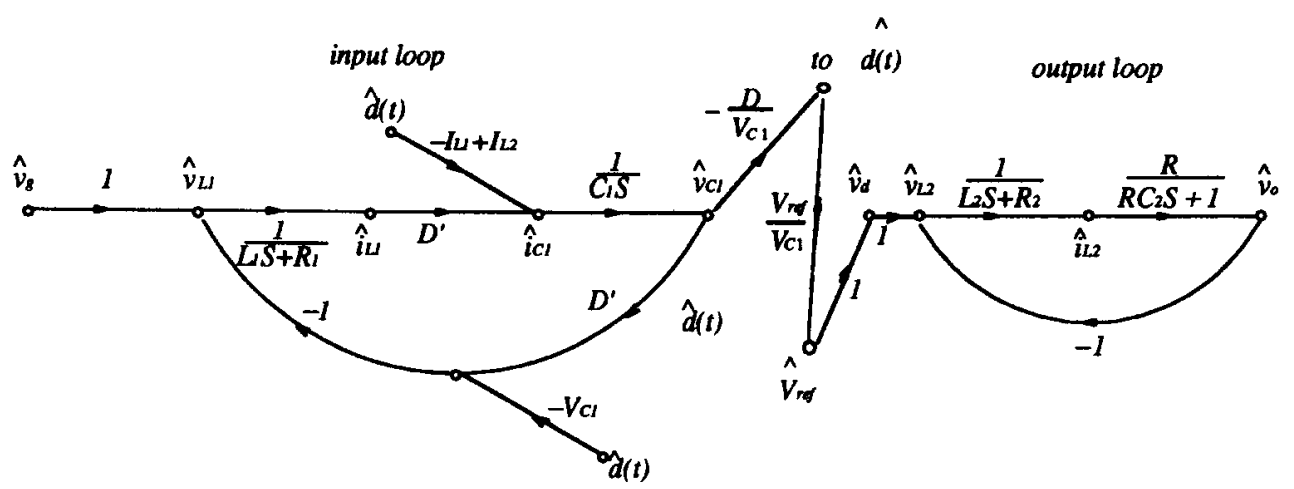

Fig. 8. The small-signal model of One-Cycle Controlled Ćuk converter.
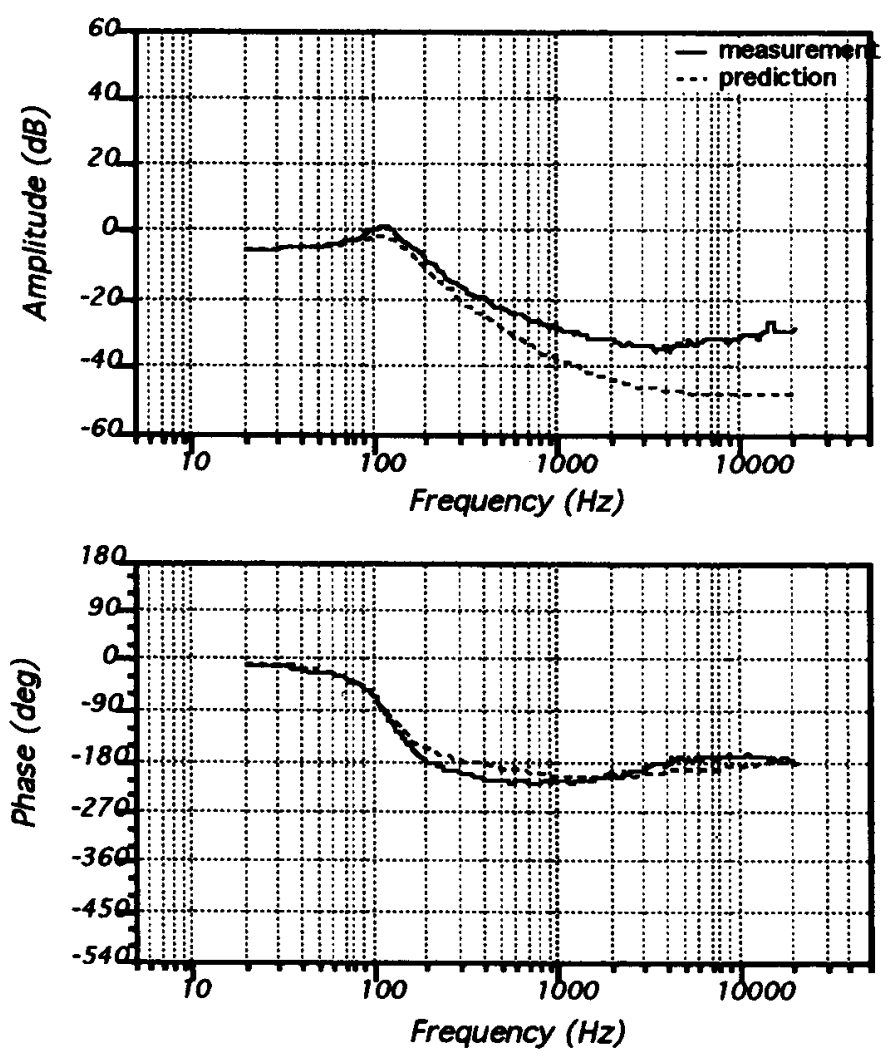

Fig. 9. The loop-gain of the One-Cycle Controlled Ćuk converter.

The linearized small-signal model of the One-Cycle Controlled switch from (8) is

$$
\hat{d}=\frac{1}{V_{C 1}} \hat{v}_{\text {ref }}-\frac{D}{V_{C 1}} \hat{v}_{C 1} \text {. }
$$

The duty-ratio of the input loop is determined by the control reference and by the feedback of the voltage across the input capacitor, as shown in (22). The output loop it is a stable linear second-order system. The linearized small-signal model of the One-Cycle Controlled Ćuk converter is shown in Fig. 8.

Consider the parasitic resistance of the input inductor $R_{1}$ and the input capacitor $R_{3}$, the linearized small-signal transfer function of the One-Cycle Controlled Cuk converter is found

$$
G=\frac{D\left(R D^{\prime 2}-R_{1} D\right)}{R D^{\prime 3}} \frac{\left(1-\frac{D L_{1} S}{R D^{\prime 2}-R_{1} D}\right)\left(1+C_{1} R_{3} S\right)}{1+\frac{C_{1}\left(R_{1}+D^{\prime 2} R_{3}\right)}{D^{\prime 2}} S+\frac{L_{1} C_{1}}{D^{\prime 2}} S^{2}} .
$$

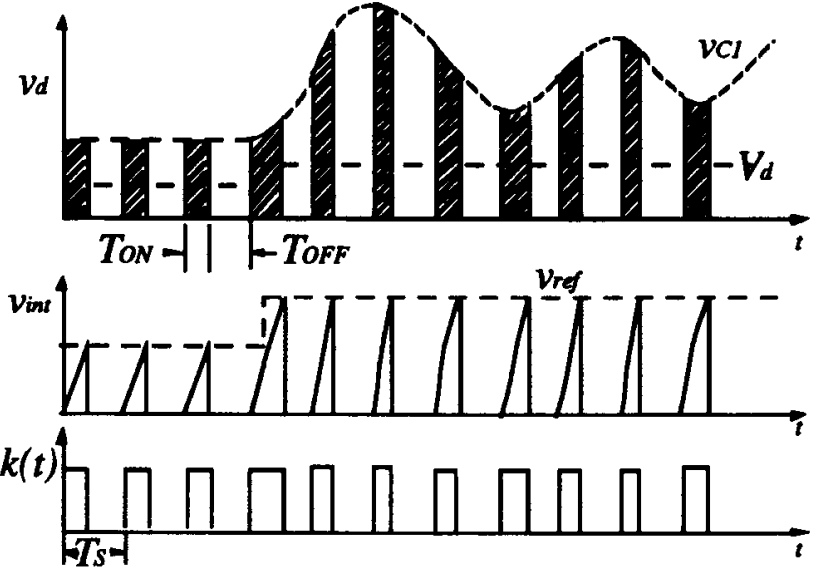

Fig. 10. Take advantage of the pulsed and nonlinear nature.

A digital injector similar to [5] was built to measure the loopgain. The predicted and the measured loop-gains are plotted in Fig. 9. The loop-gain of the One-Cycle Controlled Ćuk converter is not infinite; it is actually lower than $0 \mathrm{db}$ !

One-Cycle Control instantly controls the average value of the diode-voltage. It achieves zero steady-state error and zero dynamic-tracking error between the control reference and the average of the diode-voltage in the converging region with a finite loop-gain. This may appear physically impossible; however, a closer observation reveals that the state variables inside the loop obey physical laws. The variables actually move along the state-space trajectories shown in Fig. 7. In fact, the voltage across the diode has a finite transient, but the average of the diode voltage has instant transient (one-cycle) response to the control reference. One-Cycle Control takes advantage of the pulsed and nonlinear nature of the switching converter, and achieves instant control of the average value of the switched variable. Fig. 10 illustrates that when the control reference steps up, the voltage across the input capacitor undergoes an attenuating oscillation. The input signal of the One-Cycle Controlled switch is the capacitor voltage $v_{C 1}$. The output signal of the One-Cycle Control led switch is the diode-voltage $v_{d}$, which has an envelope equal to the capacitor voltage $v_{C 1}$. The real-time integrated value is compared with the control reference in each cycle. Therefore, the duty-ratio is precisely adjusted such that the average of the diode-voltage is exactly equal to the control reference. 


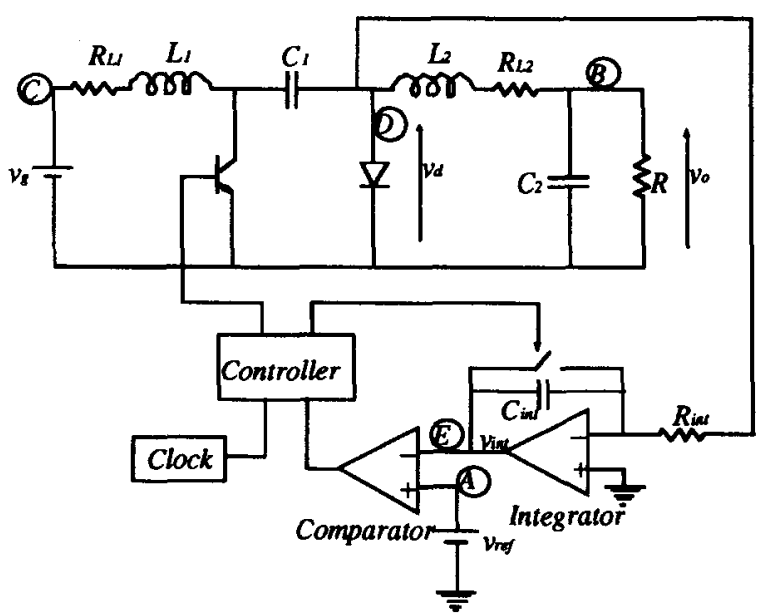

Fig. 11. The experimental Cuk converter with One-Cycle Control.

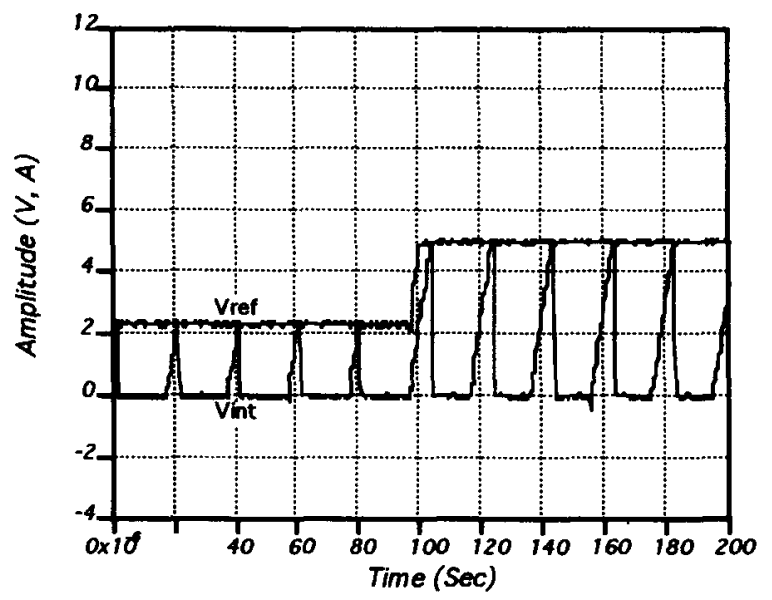

Fig. 12. Cuk converter follows step-up of the control reference.

\section{EXPERIMENTS OF ONE-CYCLE CONTROLLED ĆUK CONVERTER}

An experimental One-Cycle Controlled Cuk converter is shown in Fig. 11. The constant frequency clock pulse turn on the transistor. The diode-voltage is integrated and compared with the control reference $v_{\text {ref }}$.

When the integrated value of the diode-voltage reaches the control reference, the comparator changes its state, which turns off the transistor and resets the integrator. Five access points are set. Point $\mathrm{A}$ and Point $\mathrm{C}$ are used to inject the control reference and the power source perturbations, respectively. Point B, Point D, and Point E are used to detect the output voltage, the diode-voltage, and the integrated diode-voltage.

Experiment 1: Measure the effect of a step response of the control reference on the diode-voltage. A step up function from $2.3 \mathrm{~V}$ to $5 \mathrm{~V}$ was injected into the control reference at Point A, while the power source voltage and the load were held constant. The integrator output response was detected at Point E. The experimental results are shown in Fig. 12. Since the load and the power source voltage are constant, the integration slope is constant. When the control reference stepped up, the integration took longer to reach the control reference. The average value of the diode-voltage jumped to its new steady state in one cycle.
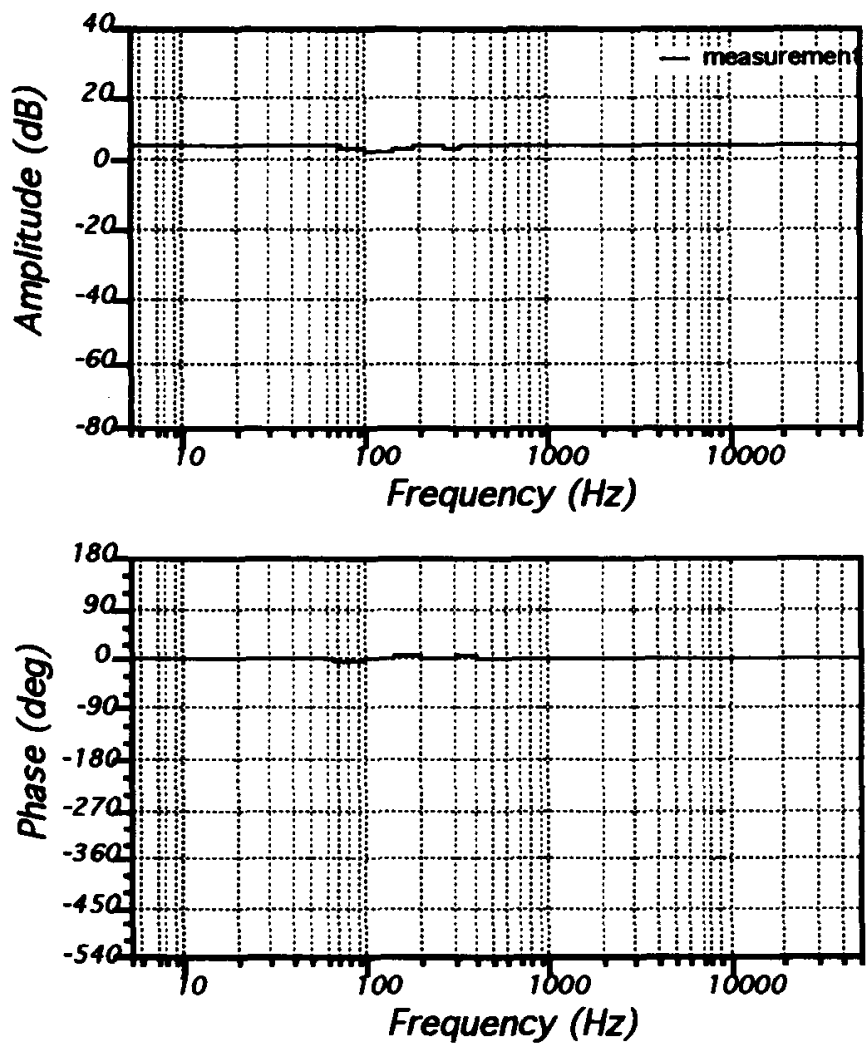

Fig. 13. The control-to-diode-voltage frequency response of the One-Cycle Controlled Ćuk converter.

Experiment 2: Measure the control-to-diode-voltage frequency response. A swept frequency signal was injected into the control reference at Point A, while the diode-voltage response was measured at Point D. The experimental result is plotted in Fig. 13. Since the average value of the diodevoltage was fully controlled by the control reference, it was predicted that the frequency response of the diode-voltage to the control reference should be flat. The detected frequency response has a very flat amplitude response and phase lag. Since the diode-voltage is not exactly zero when the transistor is on, the frequency response is not completely flat.

Experiment 3: Measure the control-to-output frequency response. A swept frequency signal was injected into the control reference at Point $\mathrm{A}$, and the output-voltage response was measured at Point B. The experimental result is plotted in Fig. 14. As predicted in the previous section, the frequency response of the One-Cycle Controlled Cuk converter is equivalent to a second-order system.

Experiment 4: Measure the power source-to-output frequency response. A swept frequency signal was injected into the power source voltage at Point $C$, while the output-voltage response was measured at Point $\mathrm{B}$. The experimental result is plotted in Fig. 15. It was expected that the system should completely reject the power source voltage perturbation. However, the experimental data show that there were leakages of the power source perturbation, especially when the swept frequency was near the corner frequency, $300 \mathrm{~Hz}$, of the input filter. This was due to the fact that real components are not ideal and the wire wrap circuit has some AC coupling. 

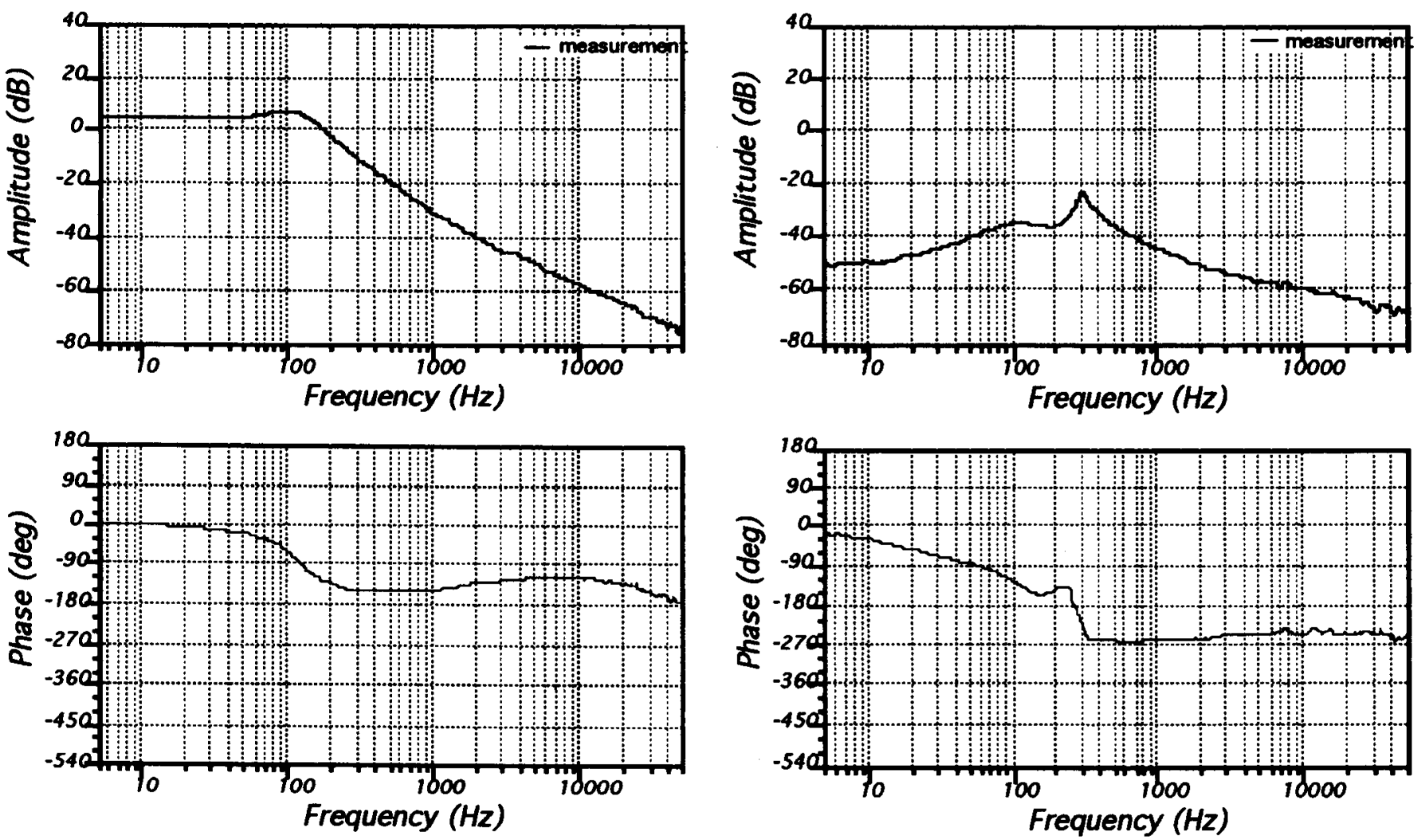

Fig. 14. The control-to-output frequency response of the One-Cycle Controlled Ćuk converter.

\section{SUMMARY}

An One-Cycle Controlled switch is globally stable, since its input signal and the control reference are independent variables. However, if the One-Cycle Controlled switch is embedded in a complex system such that the input signal of the switch is a function of other state variables, the stability for the system may not be global. The Flow-Graph model is employed to study the large-signal and the smallsignal dynamic behavior of the One-Cycle Controlled Cuk converter. The large-signal dynamic simulation shows that although the One-Cycle Controlled system is not globally stable, with proper limitation of the duty-ratio, a globally stability can be realized. The One-Cycle Control achieves zero steady-state error and zero dynamic-tracking error between the control reference and the average of the switched variable in the converging region. The small-signal model and loopgain measurements show that the One-Cycle Control has a loop-gain below $0 \mathrm{db}$ ! This may appear physically impossible; however, a closer observation reveals that the state variables obey physical laws. The transients of the capacitor voltage and the inductor current are not instantaneous. The One-Cycle Control takes advantage of the pulsed and nonlinear nature and achieves the instant control over the average value of the switched variable, the diode-voltage.

The experiments show that the One-Cycle Controlled Ćuk converter is stable with the duty-ratio limitation. The diodevoltage follows the control reference in one cycle, and rejects the power source perturbations in one cycle. The input dynamics are blocked by the One-Cycle Control; therefore, the Cuk

Fig. 15. The power source-to-output frequency response of the One-Cycle Controlled Ćuk converter.

converter behaves like a second-order system. When the dutyratio limitation is larger than $\frac{v_{\text {ref }}}{V_{2}}$, an oscillation is observed in the input loop. It is interesting that the average of the diodevoltage still follows the control reference in one cycle even the input loop is unstable, since the dynamic of the input loop is blocked by the One-Cycle Control switch.

One-Cycle Control is a powerful nonlinear control method for switching circuits and systems. It provides fast dynamictracking and excellent perturbation-rejection.

\section{REFERENCES}

[1] K. M. Smedley, "Control art of switching converters," Ph.D. Thesis, California Institute of Technology, Pasadena, 1990.

[2] K. M. Smedley and S. Ćuk, "One-Cycle Control of switching converters," in IEEE Power Electronics Specialists Conf., 1991 Record, pp. 1173-1180 (IEEE Pub. 91ch3163-3). See also US Patent 5,278,490.

[3] _ "One-Cycle Control of switching converters," IEEE Trans. Power Electron., vol. 10, no. 6, pp. 625-633, Nov. 1995.

[4] Trans. Power Electron., vol. 9, no. 4 pp. 405-413, July 1994.

[5] B. H. Cho and F. C. Lee, "Measurement of loop gain with the digital modulator," IEEE Power Electronics Specialists Conf., 1984 Record, pp. 484-491 (IEEE Pub. 84ch2000-8).

[6] W. E. Reynolds and J. Wolf, TUTSIM User's Mannal, 1987.

[7] S. Ćuk and R. D. Middlebrook, "Advances in switched mode power conversion vols. I, II, III," TESLAco 1981 and 1983.

Keyue M. Smedley, (M'87) for a photograph and biography, see this issue, p. 633 .

Slobodan Ćuk, (M'77-SM'95) for a photograph and biography, see this issue, p. 633. 